\title{
Christian Identity y el paradigma teo-político de Wesley Swift en el contexto de la formación del cristianismo antisemita estadounidense*
}

\author{
Ana-Laura Bochicchio** \\ Universidad Nacional de Tierra del Fuego-Instituto de Cultura, \\ Sociedad y Estado, Argentina \\ https://doi.org/10.15446/frdcp.n21.90334
}

\section{Resumen}

Wesley Swift fue un ministro religioso estadounidense con un rol clave en la formación de Christian Identity, paradigma teo-político cristiano antisemita al servicio de la extrema derecha de la posguerra. Este artículo rastrea las influencias que inspiraron a Swift y sus re-significaciones a la luz de las necesidades de la extrema derecha en el contexto específico de paranoia general durante las primeras décadas de la Guerra Fría. Analizar la construcción de teo-política de Swift a partir de su antropología, soteriología, demonología y escatología permite comprender el proceso de génesis de un culto como Christian Identity, el cual parece marginal y exótico, pero tiene mucho que ver con su coyuntura de surgimiento.

Palabras clave: antisemitismo; Estados Unidos; anticomunismo; Christian Identity; Wesley Swift.

\footnotetext{
* Artículo recibido: 1º de febrero de 2021 / Aceptado: 3 de agosto de 2021 / Modificado: 15 de agosto de 2021. El artículo es producto de la investigación para la tesis de doctorado en Historia, titulada "Salvación por la sola raza: los impulsos culturales norteamericanos en los sermones Christian Identity de Wesley A. Swift (1954-1967)", en la Universidad de Buenos Aires, Argentina. Contó con el financiamiento de una beca doctoral de la Secretaría de Ciencia y Técnica de dicha Universidad.

*** Doctora en Historia por la Universidad de Buenos Aires, Argentina. Profesora de la Universidad Nacional de Tierra del Fuego-Instituto de Cultura, Sociedad y Estado, Argentina. Correo electrónico: albochicchio@untdf.edu.ar iD https://orcid.org/0000-0003-0302-0595
}

\section{Cómo citar}

Bochicchio, A. L. (2022). Christian Identity y el paradigma teo-político de Wesley Swift en el contexto de la formación del cristianismo antisemita estadounidense. FORUM. RevistaDepartamentoCienciaPolítica,21,98-121.https://doi.org/10.15446/frdcp.n21.90334 


\title{
Christian Identity and Wesley Swift's Theo-Political Paradigm in the Context of the Formation of American Anti-Semitic Christianity
}

\begin{abstract}
Wesley Swift was an American religious minister with a key role in the formation of Christian Identity, an anti-Semitic Christian theo-political paradigm at the service of the post-war far right. This article traces the influences that inspired Swift and his resignifications according to the needs of the extreme right in the specific context of general paranoia during the first decades of the Cold War. Analyzing Swift's theo-politics from his anthropology, soteriology, demonology, and eschatology allows us to understand the process of genesis of a cult like Christian Identity, which seems marginal and exotic, but has a lot to do with the context in which it appeared.
\end{abstract}

Keywords: antisemitism; United States; anti-Communism; Christian Identity; Wesley Swift.

\section{Introducción}

Luego de la Segunda Guerra Mundial, el extremismo de derecha en los Estados Unidos se consolidó en torno a un antisemitismo que sincretizó las ansiedades anticomunistas y segregacionistas predominantes entre la población blanca durante las décadas de 1950 y 1960. Este proceso se materializó mediante la formación de organizaciones de diferente índole - Ku Klux Klan, neonazis, milicias-, que comparten una ideología supremacista/nacionalista blanca que coloca a la figura del judío como el principal enemigo de los Estados Unidos y de las "naciones blancas". La religión ha jugado un rol clave en dicho proceso. La consolidación del culto Christian Identity (CI) en la década de 1950 brindó a la extrema derecha una sustancia teológica para su antisemitismo, permitiendo legitimar su política desde el imaginario cristiano. Por otro lado, luego de 1945 se dio un proceso de internacionalización del concepto de "raza aria". Tanto en el discurso como en la formación de alianzas, se conformó un nacionalismo blanco, basado en la idea de que las naciones blancas europeas y los Estados Unidos comparten una tradición cultural común que surge de un componente racial compartido (Kaplan y Weinberg, 1998).

El concepto de "extremismo de derecha" suele estar asociado al de "desposeídos", noción acuñada por Daniel Bell en 1962 para referirse a los sectores de la población que creen estar perdiendo estatus social (Bell, 2008). Generalmente este concepto ha sido utilizado por los académicos estadounidenses para referirse a los ciudadanos blancos 
nativos que, ante la amenaza de la incorporación en la vida política y social de sectores no blancos o blancos extranjeros, ha reaccionado volcándose al extremismo de derecha. Tanto el nativismo como la supremacía blanca y el antisemitismo contemporáneo son reacciones al sentimiento de pérdida de rango de algunos grupos frente a otros, frecuentemente identificados con extranjeros o razas de color por el grupo afectado.

La política norteamericana en general se ha visto influida a lo largo de su historia por una patología a la que Richard Hofstadter llama "estilo paranoide", la cual define como un sentimiento de persecución que se sistematiza en grandes teorías conspirativas (Hofstadter, 1996, p. 4). Lo que distingue a este estilo es que sus miembros "consideran a una conspiración 'vasta' o 'gigante' como la fuerza motivadora de los eventos históricos. La historia es una conspiración puesta en marcha por fuerzas demoníacas de un poder casi trascendental" (Hofstadter, 1996, p. 29) ${ }^{1}$. Un sector en el que particularmente se destacan estos rasgos paranoides es la extrema derecha. De todos modos, el estilo paranoide es una constante de la vida política norteamericana, razón por la cual se instituye como una representación identitaria que percibe la relación de los estadounidenses con los otros de un modo específico y que se encuentra impregnado en el inconsciente cultural y en el sentido común de la población blanca hegemónica ${ }^{2}$. Por eso mismo, las teorías de la conspiración que derivan del imaginario paranoide pueden variar a lo largo de la historia, pero se mantienen como un modo específico de significar el vínculo con los extranjeros o con las minorías étnicas no blancas.

Este estilo se alimenta de los imaginarios judeocristianos que atraviesan la vida cultural norteamericana. Desde sus orígenes los Estados Unidos se concibieron a sí mismos como una nación excepcional, elegida por la Providencia. Tales imaginarios excepcionalistas requieren que exista un enemigo demoníaco que encarne las fuerzas del mal que combaten a dicha Providencia. El dualismo de esta cosmovisión paranoide implica que el conflicto se exprese, a su vez, en términos escatológicos. Así, la "realidad" político-social es entendida como producto de la historia de la salvación, en la que se libra una constante lucha entre fuerzas divinas y diabólicas.

Christian Identity es un culto que sirve a la legitimación religiosa del racismo y en particular del antisemitismo presentes en el estilo paranoide de la extrema derecha. Su formación en los Estados Unidos fue resultado de un proceso de metamorfosis y radicalización

1. Énfasis del original. Las traducciones del inglés al español son de la autora.

2. El estilo paranoide no ha sido propiedad exclusiva del extremismo de derecha. En general, la política oficial estadounidense también practica el estilo paranoide, siendo el macartismo el ejemplo más notorio de ello. Sin embargo, existe una diferencia entre el extremismo y el conservadurismo oficial que tiene que ver con que este último no rechaza el statu quo como sí lo hace la extrema derecha. 
del anglo-israelismo. Este surgió en Gran Bretaña a mediados del siglo XIX como una corriente revisionista bíblica. Su argumento principal era que los descendientes biológicos de las diez tribus perdidas de Israel no son los judíos, sino las naciones cristianas europeas, teniendo entre ellas un rol primordial el Reino Unido, progenie de Efraín -hijo de José y nieto de Jacob-. Fue John Wilson, intelectual escocés, quien en 1840 institucionalizó al anglo-israelismo con su obra Lectures on Our Israelitish Origins. Wilson (1840/1880) intentó demostrar a partir del análisis lingüístico e institucional que la migración de las tribus perdidas de Israel se desarrolló hacia el norte de Europa, especialmente hacia Gran Bretaña. Este mecanismo teórico supuso que los judíos fueran extirpados de su vínculo biológico con las tribus de Israel, diferenciando al reino de Israel del reino de Judá, de donde descenderían los judíos de la actualidad. Así, para los anglo-israelitas los judíos dejan de ser descendientes de Israel, rol que se apropian para ellos mismos.

A finales del siglo XIX el anglo-israelismo llegó a los Estados Unidos a través de los viajes "misioneros" de Edward Hine, discípulo de Wilson. A esta nación, Hine la identificó con Manasés, hermano de Efraín. Concretamente, durante las décadas de 1920 y 1930 el anglo-israelismo comenzó a radicalizarse en manos norteamericanas y canadienses debido a su adopción por parte de una serie de personajes asociados a la derecha racista de ambos países. Así, las ideas originales de Wilson fueron trasmutando hacia la formación de un nuevo culto que se consolidó como sumamente antisemita a mediados del siglo XX, a partir de la resignificación y combinación de parámetros demonológicos judeocristianos arcaicos y de la tradición antisemita euro-americana contemporánea.

Tres fueron los principales ministros que contribuyeron a consolidar a Christian Identity durante la segunda mitad del siglo XX en Estados Unidos: Wesley Albert Swift, William Potter Gale y Bertrand Comparet. Han sido principalmente los sermones de Wesley Swift los que dieron forma a la teología antisemita del culto ya que los otros dos predicadores fueron formados bajo su égida. La base de la teología de Swift deriva de tres ideas básicas: la creencia en la paternidad divina de la humanidad blanca -la cual es indistintamente llamada "israelita", "aria”, "adámica” o "caucásica"-, la creencia en la paternidad satánica biológica de los judíos y el milenarismo racial, es decir, la certeza de que en el futuro acontecerá un enfrentamiento escatológico entre ambas raíces raciales que dará como resultado el triunfo de la raza blanca.

La política oficial cumple un rol fundamental a la hora de establecer un marco hegemónico desde el cual Identity es capaz de actuar ya que, como sugiere Marc Angenot, todo lo que se dice, escribe y argumenta en un estado de sociedad constituye el discurso social permitido por la hegemonía discursiva de esa sociedad (Angenot, 2010). En ese sentido, este artículo pretende contribuir al área de los estudios culturales ya que 
analizando la construcción teo-política de Wesley Swift resulta posible comprender el proceso más amplio de génesis y consolidación de Christian Identity, el cual parece marginal y exótico, pero tiene mucho que ver con la sociedad estadounidense durante su contexto de surgimiento. Al comprender esta estructura teológica, es posible rastrear las influencias que inspiraron a Swift y sus resignificaciones a la luz de las necesidades de la extrema derecha en el contexto específico de paranoia general durante las primeras décadas de la Guerra Fría en Estados Unidos.

El conflicto bipolar significó el recrudecimiento de un violento anticomunismo que se arraigó con fuerza en todas las áreas de la sociedad. Esto significó que existiese un elevado grado de rechazo cultural hacia el comunismo, el cual estuvo acompañado del temor a la infiltración doméstica del enemigo rojo. A nivel oficial, el aspecto más extremo de este imaginario del "enemigo interno" se consolidó en la figura del Senador Joseph McCarthy (Republicano-Wisconsin), quien entre los años 1950 y 1954 acusó de infiltración comunista al partido demócrata y al Departamento de Estado. McCarthy reflejaba el imaginario anticomunista norteamericano, el cual tenía características irracionales y paranoides que tendían a sobrestimar el avance soviético ${ }^{3}$.

Un pánico tan irracional fue consecuencia de lo que Tom Engelhardt denomina desesperación triunfalista, es decir la ansiedad generada por el triunfo no consumado plenamente y por las ansiedades de la posible destrucción nuclear (Engelhardt, 1997, p. 27). El hecho de que la Unión Soviética, potencia con valores contrarios al capitalismo, al sistema democrático, a la religión cristiana y al individualismo haya sido capaz de imponerse como un oponente de alto rango, significó una crisis de identidad muy fuerte entre la sociedad estadounidense.

A este conflicto se le sumó otra cara que afectaba especialmente a la identidad hegemónica blanca: la lucha de los afroamericanos por la obtención de los Derechos Civiles. Desde la década de 1950, estos intensificaron las medidas para acabar con la segregación racial. La Guerra Fría constituyó una coyuntura propicia para ello debido a que Estados Unidos debía encarar una limpieza de su propia imagen ante la opinión pública mundial. La legislación segregacionista Jim Crow ${ }^{4}$ era la mancha más oscura del sistema "democrático-liberal" y, por lo tanto, contradecía la imagen internacional que Estados Unidos quería mostrar frente al enemigo "totalitario" soviético. Así, la

3. El Partido Comunista de Estados Unidos (PCUSA) que contaba con 79000 miembros en 1944, pasó a tener 23000 miembros en 1954 (Ceplair, 2011, p. 102).

4. Las leyes Jim Crow fueron un conjunto legislativo aplicado en el sur estadounidense desde la década de 1870. Promovía la segregación racial de blancos y negros en toda institución y espacio público bajo el principio de "separados pero iguales". 
población blanca más conservadora sentía que una doble amenaza roja y negra afectaba su statu quo. Esto condujo a que amplios sectores de esta se volcaran hacia tendencias de extrema derecha racista ante la sensación de "desposesión".

No se debe olvidar que Estados Unidos es una sociedad en la que el racismo cumple una función social específica para ciertos sectores poderosos que lo divulgaban e incluso para los blancos más pobres. Estos sienten que gozan de un estatus privilegiado por sobre los que están étnicamente "por debajo" de ellos. Así, el racismo es de gran utilidad a la hora de esconder los verdaderos vínculos de poder entre blancos. Este mecanismo fue bien explicado por el ex-presidente Lyndon Johnson -periodo presidencial 1963-1969-: "si logras convencer al hombre blanco más bajo de que él es superior que el más alto de los hombres de color, no se dará cuenta de que le estás tomando su bolsillo. Tráele alguien a quien mirar desde arriba y vaciará sus bolsillos para ti” (Isenberg, 2016, p. 264).

Justamente, Christian Identity cumple la funcionalidad de seguir reproduciendo este modelo de dominación. Es cierto que lo hace desde el extremo del abanico político. Pero, en definitiva, asegura el modelo entre aquellos que se suponen al margen de él.

Las fuentes principales utilizadas son los sermones de Wesley Swift entre 1954 y $1967^{5}$. La selección de este periodo surge del corte generado en 1954 por la Brown v. Board of Education, fallo de la Corte Suprema que terminó con la segregación escolar en los colegios públicos de Estados Unidos. Este acontecimiento desencadenó una oleada de violencia racial, por lo que es posible considerarlo el puntapié del crecimiento de las agrupaciones de extrema derecha. Por otra parte, ese mismo año finalizó el periodo macartista. Quedó un vacío de representación que para muchos sectores blancos del país fue llenado por estas agrupaciones. Por su parte, el año 1967 coincide con una nueva etapa de la derecha racista estadounidense, más volcada hacia la acción miliciana y el terrorismo doméstico, influenciado por la teo-política Identity. Esto fue consecuencia del asesinato de George Lincoln Rockwell, líder del American Nazi Party. Su muerte significó un cisma que dio lugar a numerosas agrupaciones con intenciones terroristas más marcadas (Simonelli, 1999).

\section{Wesley Swift y Christian Identity en Los Ángeles}

Wesley Swift nació en Nueva Jersey el 6 de septiembre de 1913. Hijo de un pastor metodista, se ordenó como ministro de tal denominación a los 18 años. Continuó sus

\footnotetext{
5. Los sermones aquí utilizados han sido transcritos por Ella Rose Tucker-Mast luego de la muerte de Swift, a partir de grabaciones en casetes, lo cual da cuenta de la influencia posterior que estos sermones alcanzaron al tener mayor divulgación, sobre todo en Internet. https://swift.christogenea.org/
} 
estudios en Los Ángeles, donde conoció el anglo-israelismo por medio de Charles F. Parham, uno de los líderes del movimiento pentecostal (Roberts, 2003, p. 12). La ciudad fue centro de las actividades anglo-israelitas durante la década de 1930, lo cual llevaría directamente a la formación de Christian Identity allí mismo.

Asimismo, en 1949 Los Ángeles fue la locación de un importante evento dentro de la historia del movimiento evangélico en Estados Unidos. Entre el 25 de septiembre y el 20 de noviembre, el predicador Billy Graham organizó su primera cruzada evangélica en la ciudad. Esta campaña lo consolidó como el más influyente y prestigioso pastor evangélico estadounidense de la Guerra Fría. Este acontecimiento fue síntoma del despertar religioso que estaba experimentando el país. Tal como la Guerra Fría doméstica lo exigía, la religión se fue combinando con la política desde un predicamento que combinaba referencias bíblicas con la actualidad político-social de Estados Unidos, lo cual convocaba a la población a defender los valores cristianos y a delatar la supuesta infiltración soviética en el país (Gunn, 2009).

Por su parte y en tal contexto, la carrera de Wesley Swift no solo se cimentó sobre actividades religiosas, sino también políticas. Durante la década de 1940 dirigió varias instituciones anglo-israelitas del área de Los Ángeles, tales como el Great Pyramid Club, la Anglo-Saxon Christian Congregation y el Anglo-Saxon Bible Study Group. En 1946 Swift fundó el principal órgano de difusión de Christian Identity: la Anglo-Saxon Christian Congregation en el distrito de Lancaster.

En 1957 cambió su nombre por el de Church of Jesus Christ Christian, manteniéndose en vigencia hasta la década del 2000 por medio del principal sucesor de Swift, Richard Butler. También presidió organizaciones políticas como la California Anti-Communist League y la California Pastors Committee Against Communism. Durante la década de 1960, Swift formó parte de los California Rangers y la Christian Defense League, organizaciones relacionadas con William Potter Gale, protegido de Swift que posteriormente se convertiría en una figura Identity de renombre como parte del "triunvirato Comparet-Swift-Gale que definió a Christian Identity en California” (Barkun, 1997, p. 66). Según Ralph Roy, este conjunto de organizaciones constituyó los elementos racistas más fuertes de la costa oeste entre los años de 1940 y los primeros años de la década de 1950 (Roy, 1953, p. 103).

Con respecto a la audiencia de Wesley Swift, los archivos del FBI recuentan un promedio de entre 40 y 100 personas asistentes a sus sermones durante la década de 1950 y 1960 en diferentes locaciones ${ }^{6}$. Si bien no se conoce la procedencia de todos

6. Federal Bureau of Investigation (FBI), Estados Unidos, archivo 157-355454, www.archive.org/details/ SWIFTWesleyA.HQ157355454141206pp/page/n19/mode/2up. El archivo 157-355454 del HQ del FBI es un archivo de 206 páginas sobre el reverendo Wesley Albert Swift, que cubre el período de abril de 1948 a febrero de 1969. 
estos públicos, sí se sabe que en Los Ángeles la Church of Jesus Christ Christian realizaban encuentros ante el Friday Morning Club y el Hollywood Women's Club, ambas agrupaciones de mujeres. Resulta, entonces, que el público de Wesley Swift estaba dividido entre los sectores segregacionistas y un círculo de mujeres locales.

Ahora bien, ¿por qué estas mujeres buscaban la guía espiritual y política de un culto que era protagonista entre los círculos de extrema derecha más importantes del país? Concretamente durante la Guerra Fría, las organizaciones civiles femeninas conservadoras cobraron singular importancia puesto que en tal clima de época se creía que la institución familiar corría un particular peligro de deterioro si se dejaba actuar a la amenaza comunista. Ellas creían que los niños corrían el riesgo de ser cooptados, manipulados y pervertidos en la batalla por las mentes que Estados Unidos disputaba contra el comunismo. Y como su cuidado era tarea del ámbito exclusivo de las mujeres, eso condujo a que muchas de ellas se sintieran en la obligación de estar alertas frente a semejante amenaza (Bochicchio, 2020; Brennan, 2008; Laville, 2017).

La integración racial era otro problema que estas organizaciones sentían que debían enfrentar. El hecho de que la ideología de la supremacía blanca contuviera la necesidad de la defensa de las mujeres blancas, acosadas por la voracidad sexual de los negros, implicó que algunas mujeres, sobre todo en el sur de Estados Unidos, se opusieran fervientemente a la integración escolar. El mito de la violación era muy común en los Estados Unidos desde la abolición de la esclavitud negra. Este respondía a un imaginario que describía a los negros como voraces depredadores sexuales cuyas principales víctimas eran las inocentes mujeres blancas (Lindquist Dorr, 2004). Así pues, el discurso de Swift coincidía con las necesidades de época de ciertos sectores blancos, a los que pertenecían estas mujeres.

Al mismo tiempo, sus sermones marcaron un giro que influyó en la historia de la extrema derecha, la cual se fue radicalizando en una transición que fue evolucionando hacia la acción directa. Si bien en este proceso no influyó solamente Swift, su construcción teocrática colaboró ya sea de manera directa o indirecta en la formación de un tipo de discurso que habilitó el desplazamiento de la extrema derecha hacia la violencia directa. Tal como afirma M. Barkun, "La evolución de Identity en los ' 70 y ' 80 se dio en gran parte en función de aquellos influenciados de un modo u otro por los escritos y el predicamento de Wesley Swift" (1997, p. 49).

Es cierto que la totalidad de las variantes de extrema derecha que se desarrollaron desde 1970 hasta la actualidad no promulgan la religión cristiana en versión Identity. Sin embargo, en general el discurso de la extrema derecha está plagado, sean conscientes o no, de representaciones y resignificaciones del discurso construido por Christian Identity en sus primeros años. 


\section{El paradigma teológico de Wesley Swift}

Al ser Christian Identity un culto cristiano, la Biblia es la principal fuente de sus especulaciones teológicas. Las Escrituras en sí no contienen una doctrina racista, sino que es el rol del exégeta el que permite incorporar los elementos que guían su lectura. En efecto, la lectura de la Biblia ha sido atravesada en muchas ocasiones por la interpretación racista que recurrió a las Escrituras para encontrar en ellas la justificación divina de ideologías y prácticas racistas. Es sobre todo el libro del Génesis el que resulta especialmente funcional a tal propósito puesto que narra la historia de la creación del hombre y la mujer, sus primeras descendencias, su posterior corrupción, destrucción y regeneración por medio del Diluvio, todo lo cual puede ser fácilmente manipulado para explicar las diferencias del género humano.

Es posible considerar a Christian Identity como un modelo teológico que posee la serie de elementos necesarios para constituir un paradigma cristiano. Según Charles H. Roberts, el mismo debe poseer un conjunto de creencias, axiomas y presupuestos que enmarcan el modo en qué un teólogo interpreta las Escrituras. El autor sugiere que Identity constituye un sistema teológico debido a que sus creencias "se basan en un paradigma que interpreta la totalidad de la Escritura, desde el comienzo, a partir de una perspectiva racial y no pactual" (Roberts, 2003, pp. 1-3). Esto significa que la teología de Christian Identity se centra en la cuestión racial para explicar el vínculo existente entre Dios y su pueblo elegido, el cual está constituido únicamente por la raza blanca. Entonces, la raza como una cuestión biológica que refleja la esencia espiritual del ser es el elemento que atraviesa todos los componentes del paradigma teológico de Swift. Es el parámetro que explica tanto su propia doctrina de la salvación como la antropología, la cristología, la demonología y la escatología.

\section{Antropología y soteriología}

Siendo el Génesis un libro tan importante a la hora de fundamentar la supremacía blanca, no resulta extraño que, para reforzar esta cualidad, Wesley Swift haya sumado a su construcción teológica la exégesis de libros apócrifos del Antiguo Testamento que rescriben y completan de manera fantástica las narraciones del Génesis ${ }^{7}$. Esta literatura se refiere con frecuencia a los ángeles caídos y el modo en que su pecado afectó a la humanidad. La principal fuente apócrifa de estos relatos demonológicos es El libro de los Vigilantes, perteneciente a 1 Henoc. En el conjunto de libros que conforman el ciclo

\footnotetext{
7. Los libros apócrifos del Antiguo Testamento fueron escritos entre el año 200 a.C. y 200 d.C., periodo intertestamentario. Por lo general son obras anónimas referidas o atribuidas a un personaje perteneciente al canon hebreo.
} 
de Henoc, el motor de la historia de la redención es equivalente a la cosmovisión maniquea del estilo paranoide al que responde la construcción teo-política de Christian Identity. Ambas suponen que todos los hechos de la historia manifiestan el avance o retroceso de las fuerzas demoníacas, todo en función de un futuro escatológico.

Tal visión supera las dificultades que el Génesis presenta para Christian Identity a la hora de caracterizar el origen y la naturaleza del mal. Para el canon cristiano el mal es un producto humano que aparece en la tierra como consecuencia de la desobediencia original, producto del libre albedrío de Adán y Eva (Sarna, 1970, p. 24). En cambio, en la literatura apócrifa del Antiguo Testamento, el mal tiene entidad propia como producto de la influencia de los ángeles caídos que, al rebelarse contra Dios y ser condenados a permanecer en la tierra, infiltran el pecado en el mundo. La importancia de esta concepción radica en que da por sentado el hecho de que la naturaleza humana es esencialmente incapaz de pecar por sí misma. En el caso de Christian Identity, a tal noción antropológica se suma la idea de que los únicos descendientes de Adán y, por lo tanto, los únicos seres que entran en la categoría humana, son los hombres y mujeres blancos ${ }^{8}$. Consecuentemente, solo ellos poseen la condición de impecabilidad.

A diferencia de la tradición hebrea original, según esta concepción, el pacto divino no se realizó con una nación, sino con una raza. Para Christian Identity, los descendientes blancos de Adán son una raza distribuida entre las naciones blancas cristianas a partir de un vínculo biológico real con los israelitas originales, que habrían sido los primeros hombres blancos encarnados en la tierra. Entonces, siguiendo la evolución de las tribus de Israel desde Set ${ }^{9}$ hasta la actualidad, al igual que los anglo-israelitas, Swift suponía que, a partir de las descendencias de Efraín y Manasés, hijos de José - patriarca hijo de Jacob-, provienen las razas anglosajonas de Inglaterra y Estados Unidos. Así, aseguraba a sus oyentes que "los pueblos anglosajones pertenecen a la casa de José en el mundo actual. Y ustedes provienen de la casa de Abraham a través de José y las líneas setitas de Henoc, las cuales existieron en Egipto previamente al Diluvio"10.

El destino de la progenie adámica es, según Swift,

Valorar la plenitud de la estatura de Cristo, Su Gloria y Su poder ya que vuestra esperanza es el Cristo dentro de ustedes y van a alcanzar tal nivel. Ello fue destinado antes de la creación del mundo. Ustedes son el pueblo al que Él predestinó a conformar la imagen del Hijo - su encarnación ${ }^{11}$.

8. Wesley Swift, The Bible and the Race of Destiny, 15 de enero de 1962, https://swift.christogenea.org/

9. Tercer hijo varón de Adán y Eva, principal patriarca del linaje de Israel.

10. Wesley Swift, The Covenant Race, 12 de febrero de 1963, https://swift.christogenea.org/

11. Wesley Swift, The Mystery of Christ and His Kingdom: His Church, 27 de agosto de 1961. https://swift. christogenea.org/ 
Puede observarse que para Swift la categoría de Cristo incluye a todos los hombres y mujeres caucásicos puesto que potencialmente poseen en su interior la totalidad de la substancia divina. Por lo tanto, la diferencia del hombre blanco con Jesucristo radica en que este fue el mismo Dios encarnado, cuya misión consistió en restaurar al mundo corrompido por culpa de la mezcla interracial. Esta perspectiva supone una modificación de la misión redentora de Jesús ya que su muerte habría significado únicamente la redención del género adámico. Así, Christian Identity promulga una soteriología ${ }^{12}$ que posee una doctrina extrema de la doble predestinación calvinista ${ }^{13}$, en la que los predestinados a la salvación y los predestinados a la perdición pueden ser reconocidos por su condición racial -que refleja la esencia espiritual. No es, pues, la fe la que salva, sino la raza. Swift predicaba ante su audiencia un discurso de predestinación y salvación racial: "ustedes fueron predestinados previamente a venir al mundo... Ni uno solo de vuestra raza ha sido predestinado a las llamas flameantes ni a la perdición"14.

Para mantener esta pureza, los hijos de Dios deben evitar mezclarse con las razas que sí son de la tierra, es decir con las razas que no pertenecen al género humano. Las personas que no pertenecen a la raza adámica constituyen la categoría preadamita, es decir que su establecimiento en la tierra fue previo al de Adán y Eva ${ }^{15}$. Swift los describía como razas que fueron creadas "a partir de los elementos de la tierra" y no a partir de la esencia divina ${ }^{16}$. Esta categoría incluye a los pueblos asiáticos en general:

El primer pueblo que Dios colocó en este planeta fueron los turanios o asiáticos. Esta gente vivió y se dispersó sobre la tierra y se multiplicó e incrementó tal como narra el Génesis que lo harían... Pero recuerden que estos fueron los antiguos pueblos turanios y sus remanentes todavía pueden ser encontrados entre los chinos y un gran número de razas asiáticas ${ }^{17}$.

En el discurso de Swift, los negros se distinguen cualitativamente de los asiáticos al vincularlos con el demonio ya que estos habrían sido traídos a la tierra en naves espaciales por los ángeles caídos: "la raza negra vino a la Tierra de un modo distintivo

\footnotetext{
12. Doctrina cristiana de la Salvación.

13. El calvinismo es una rama protestante que afirma que Dios predestinó a todos los seres ya sea a la salvación o a la condenación y que tal designio es inmodificable.

14. Wesley Swift, Why We Are Here, 16 de noviembre de 1961, https://swift.christogenea.org/

15. Las teorías sobre los seres preadamitas se remontan al siglo XVII, habiendo sido el teólogo francés Isaac de La-Peyrére el primero en formularla.

16. Wesley Swift, Were All the People on the Earth Drowned in the Flood?, 2 de septiembre de 1966, https:// swift.christogenea.org/

17. Wesley Swift, The Mystery of the Corridor of Life, 10 de septiembre de 1962, https://swift.christogenea.org/
} 
e inusual... Lucifer, en su rebelión, reunió gente desde dentro de la Vía Láctea para que porten sus hachas y espadas"18. Esta particular animosidad contra los negros refleja el contexto de época, en el cual los blancos se veían amenazados por el avance de la integración racial con los afroamericanos. La idea en una revuelta de Lucifer que trae aparejada consigo a los negros es la manera en la que Swift resignificó las revueltas por los Derechos Civiles entre las décadas de 1950 y 1960.

Un punto central en la narrativa sobre la relación entre las razas de la tierra y los hijos de Dios se encuentra en la historia bíblica del Diluvio. Christian Identity asegura que el Diluvio fue un fenómeno aislado que afectó únicamente al área de la cuenca del Tarim, en China ${ }^{19}$. Por lo tanto, los seres preadamitas continuaron viviendo puesto que la voluntad de Dios solo consistió en destruir a la descendencia corrompida de su propia progenie adámica ${ }^{20}$. De este modo, los hijos de Dios continuaron reproduciéndose únicamente a través de la rama de Noé, por medio de sus tres hijos, Sem, Cam y Jafet ${ }^{21}$. Sin embargo, la semilla adámica se volvió a corromper entre los descendientes de los dos últimos, los cuales fueron absorbidos por pueblos africanos y asiáticos ${ }^{22}$. Solo a través de Sem se mantuvo viva la esencia divina, constituyendo a los pueblos caucásicos de la actualidad como descendientes de las tribus de Israel que trazan su ascendencia hasta Sem y Noé por medio de Jacob. Según esta visión, es la integración interracial la que corrompe a la progenie israelita y que, por lo tanto, es una ley divina el mantenimiento de la segregación, lo cual refleja la voluntad de vetar las leyes de integración racial en Estados Unidos. Wesley Swift afirmaba que "Dios no solo no es un integracionista, sino que su plan para el mundo es la segregación"23.

Como es posible observar en los sermones de Swift, la teología de Christian Identity concentra su discurso en torno a la descripción de la condición espiritual de la raza adámica, pretendiendo demostrar la superioridad de esta. Esta noción antropológica está íntimamente ligada a la identidad divina. De ahí que Swift afirmara que "el racismo es auto-deificación" ${ }^{24}$.

18. Wesley Swift, The Mystery of the Corridor of Life, 10 de septiembre de 1962, https://swift.christogenea.org/ 19. Wesley Swift identifica tal área como la zona afectada por el Diluvio puesto que la considera cercana al Edén, el cual cree que estaba ubicado en el Himalaya.

20. Wesley Swift, The Covenant Race, 12 de febrero de 1963, https://swift.christogenea.org/

21. Tradicionalmente se interpretó a Génesis 10 como la narración del desplazamiento de los hijos de Noé por el mundo. A Cam se lo identificó como el padre de los pueblos africanos, mientras que la categoría caucásica fue identificada con los descendientes Japhet, entre quienes se encuentran los pueblos europeos blancos y sus descendientes en el nuevo mundo.

22. Wesley Swift, The Spiritual Race, 4 de abril de 1962, https://swift.christogenea.org/

23. Wesley Swift, Understanding Equality, 21 de enero de 1963, https://swift.christogenea.org/

24. Wesley Swift, The Covenant Race, 12 de febrero de 1963, https://swift.christogenea.org/ 


\title{
Demonología
}

La demonología es el aspecto de Christian Identity que principalmente expresa los temores de la Guerra Fría doméstica, lo cual significa que es fundamentalmente un reflejo del anticomunismo, del temor a la infiltración interna y a una conspiración internacional para derrocar los valores del "estilo de vida americano". Por otro lado, comprender la demonología de Wesley Swift es esencial para vislumbrar el rol que el antisemitismo cumple entre los sectores de extrema derecha del periodo para explicar los problemas sociales y políticos que sienten estar atravesando como consecuencia de la ejecución de la tan temida "conspiración judía internacional" 25.

Michael Barkun sugiere que este antisemitismo fue la síntesis de un conjunto de elementos separados que tuvieron vigencia desde finales del siglo XIX y que por sí solos no eran esencialmente antisemitas hasta que Identity los combinó y sistematizó. Este conjunto de teorías incluye la creencia en la existencia de seres preadamitas; la idea de que la serpiente que tentó a Eva no era un reptil, sino el Diablo o un ser asociado a él; que el pecado original fue la relación sexual que este mantuvo con Eva y que, por lo tanto, Caín es malvado y transmitió tal maldad a sus descendientes (Barkun, 1997, pp. 150151). Si bien estas ideas que funcionan como antecedentes intelectuales de Christian Identity, pudieron aparecer de un modo u otro en ciertas tradiciones hebreas y cristianas, fundamentalmente en los evangelios gnósticos ${ }^{26}$, es necesario tener en cuenta que:

\begin{abstract}
Esta literatura gnóstica seguramente era desconocida para los escritores Identity que conformaron esta teología antisemita puesto que tendían a ser tanto autodidactas como graduados de pequeñas escuelas bíblicas... En la medida en que los precursores gnósticos hayan tenido alguna influencia, la misma fue altamente mediada a través de estratos irrastreables de textos intermedios (Barkun, 1997, p. 150).
\end{abstract}

Hubo principalmente dos fuentes que sirvieron de intermediarias. Una de ellas fue la obra de Charles Carroll, The Negro a Beast (1900). La segunda fue un libro británico publicado en 1927 por Sydney Bristowe, titulado Sargon the Magnificent. El primero de estos libros fue uno de los principales trabajos de transición del racismo norteamericano del siglo XIX al racismo del siglo XX. Como tal, combina argumentos de la supremacía blanca esclavista y del antisemitismo espiritual de Christian Identity.

25. El mito de la conspiración judía internacional supone la existencia de un gobierno secreto judío con poder absoluto sobre la economía, la política, la prensa y la opinión pública y cuyo objetivo es dominar al mundo para poder instalar su propio gobierno global (Cohn,1988).

26. Sobre Caín en el gnosticismo, ver: García (2009). 
Si bien Carroll no se refiere a los judíos en el libro, su interpretación de la naturaleza de Caín y su vínculo con los preadamitas son un antecedente de la teología de Wesley Swift. Carroll afirmaba que Caín era de naturaleza maligna y que su principal pecado fue mantener relaciones sexuales con "una hembra preadamita" (1900, pp. 145-150). De igual modo, para Carroll el pecado original tuvo que ver con que Adán y Eva se dejaron engañar por la "serpiente", un ser preadamita negro. Por lo tanto, aseguraba que "la Biblia es simplemente la historia del largo conflicto entre Dios y el hombre, que enfureció a Dios como resultado de las relaciones criminales del hombre con el negro" (Carroll, 1900, p. 221).

Por su parte, Sargon the Magnificent pretende ser un estudio de asiriología cuya intención es demostrar la historicidad del Génesis. Por lo tanto, Bristowe muestra sus conclusiones como el resultado de una minuciosa investigación arqueológica y lingüística que le confirma que Sargón de Akkad "no fue otro que el primer asesino de la historia - Caín" (Bristowe, 1927, p. 3). Según la autora, Caín estaba dotado de poderes supra-humanos y fue el primero en introducir la idolatría en Medio Oriente.

Al mismo tiempo, Caín construyó la primera ciudad, en la cual se impuso como gobernante ante el conjunto de preadamitas que vivían en la tierra de Nod, fuera del jardín del Edén. Entonces, habiendo sido Caín el primer fratricida de la historia, el primer constructor de un imperio multirracial con base al dominio que impuso sobre los preadamitas y quien impuso la idolatría entre estos pueblos; la autora concluye que su instigador fue el mismo diablo (Bristowe, 1927, p. 55). Los descendientes de Caín continúan manteniendo esta alianza, según la autora. De este modo, el vínculo entre Satán y las generaciones de Caín, si bien no es biológico, ya está establecido durante la década de 1920 entre los argumentos recuperados por Swift.

En America Battles the Dragon, el sermón más antiguo conservado del pastor, Swift asocia a Satanás con la Serpiente y del Dragón, vinculando este simbolismo directa y literalmente con los judíos: "Ellos [judíos] son los Hijos de la Oscuridad... se identifican a sí mismos como los hijos del maligno... hijos de la víbora y de la serpiente”27. Al mismo tiempo, el pastor aseguraba que los pueblos preadamitas solían adorar tanto a dragones como a serpientes ya que los judíos impusieron su propio simbolismo como el de falsa deidad. De este modo, a partir de un mecanismo similar al utilizado por Sydney Bristowe, Swift vinculó a los seres preadamitas con Caín por medio de la idolatría y los identifica con la serpiente ya que "Lucifer sedujo a Eva y el hijo que nació fue llamado Caín porque era el hijo de la serpiente" ${ }^{28}$. 
Esta construcción demonológica asegura que previamente al nacimiento de Caín, Lucifer y sus ángeles caídos ya habían comenzado a reproducirse con las razas de la tierra, dando luz a progenies híbridas. Según Swift, "Lucifer comenzó una mezcla con la semilla de la tierra... este fue el mestizaje en el universo" 29 . Son los libros de Henoc los que desarrollan en profundidad el tema de los ángeles caídos y la corrupción de la tierra por culpa de su reproducción con hembras humanas. El Libro de los Vigilantes (1 Hen. 6-36) extiende la tradición de Génesis 6 : 1-4, uno de los pasajes más extraños del Antiguo Testamento. El mismo reza que,

[1] Cuando los hombres comenzaron a multiplicarse sobre la tierra y les nacieron hijas, [2] los hijos de Dios vieron que estas eran hermosas y tomaron como mujeres a todas las que quisieron. [3] Entonces el Señor dijo: "Mi espíritu no va a permanecer activo para siempre en el hombre, porque este no es más que carne; por eso no vivirá más de ciento veinte años”. [4] En aquellos días -y aún después- cuando los hijos de Dios se unieron con las hijas de los hombres y ellas tuvieron hijos, había en la tierra gigantes: estos fueron los héroes famosos de la antigüedad.

Tradicionalmente, se ha considerado que la terminología hijos de Dios hace referencia a los ángeles, mientras que hijas de los hombres se refiere a la descendencia humana de Adán. Así, Gn. 6: 1-4 ha servido como base para la interpretación que sugiere la posibilidad de las relaciones sexuales entre ángeles y humanos, las cuales dan como resultado el nacimiento de diferentes tipos de seres híbridos, denominados gigantes o nefilim. El libro de los Vigilantes relata la caída de los ángeles creados por Dios que, pecando contra Él, abandonaron sus puestos en el Cielo liderados por su jefe Semyaza ${ }^{30}$ y tomaron como esposas a hembras humanas, con quienes procrearon gigantes. Esta secuencia de degeneración de los ángeles y su procreación con hembras humanas derivó directamente en el Diluvio, acto por el cual Dios decide salvar a sus elegidos y aniquilar a la progenie corrompida ${ }^{31}$.

En cuanto a la resignificación de esta tradición de los hijos de los Vigilantes, Swift negaba que los hijos de Dios mencionados en el pasaje fuesen los ángeles caídos: "[Nefilim] no debe traducirse como Hijos de Dios porque los ángeles nunca fueron llamados 'Hijos de Dios', en ningún momento Él dijo a los ángeles 'ustedes son mis hijos'32. Entonces, para Swift, los nefilim "pertenecen a un grupo bien definido de seres. Eran un tipo de huestes de ángeles que no mantuvieron su estado original"33. Por lo tanto, para Christian Identity estos seres que se reprodujeron con las hijas de Adán eran los ángeles caídos.

29. Wesley Swift, The Destruction of the Serpent, 26 de abril de 1962, https://swift.christogenea.org/

30. Uno de los nombres que recibe el diablo en los apócrifos del AT.

31. 1 Henoc 10: 15.

32. Wesley Swift, The Stream of Life, 5 de febrero de 1961, https://swift.christogenea.org/

33. Wesley Swift, There Were Giants in the Land, 24 de abril de 1963, https://swift.christogenea.org/ 
Al encarnar Adán en la tierra, sabiendo Lucifer que la misión de estos era derrotarlo, decidió infiltrar su semilla también entre los hombres blancos. En tal sentido, Swift aseguraba que:

Ellos [el diablo y sus hijos] saben que la raza de ustedes es especialmente diferente a cualquier otro pueblo de la tierra. También saben de dónde proviene vuestra raza. Ellos saben que ustedes son los hijos e hijas del Eterno y que ellos no lo son... Saben que si la raza blanca específicamente como un pueblo o una nación se despierta y descubre su identidad y su razón de ser, ellos serán desplazados de todas las naciones blancas de la tierra ${ }^{34}$.

En consecuencia, una vez que Dios colocó a sus elegidos en la tierra, Lucifer decidió procrear un hijo con Eva. Y tal como lo exige el estilo paranoide, Wesley Swift interpretaba tal designo en términos de conspiración: "la gran conspiración de Lucifer consiste en tratar de mestizar vuestra raza y destruir su receptividad espiritual... Él quisiera que ustedes se revelen contra las leyes de Dios" ${ }^{35}$. Así pues, Caín fue el producto de la seducción de Satanás sobre Eva. Este acto fue el pecado original ${ }^{36}$. La paternidad satánica de Caín, por lo tanto, es un elemento central para Christian Identity. A partir de esta noción surge la teoría de las "dos semillas". Esta supone que de Eva nacieron dos descendencias raciales y espiritualmente diferentes. Una de ellas es la semilla de paternidad adámica, es decir la de Abel - que no tuvo descendencia-y la de Set, cuyo linaje está constituido por las actuales naciones blancas. La otra semilla, en cambio, es la diabólica o cainita, es decir los descendientes de Caín, quienes no pertenecen a la genealogía adámica.

A partir de esta semilla, Christian Identity es capaz de vincular al demonio con los judíos de la actualidad. Lo particular del discurso demonológico de Swift es que los judíos existen en todas las razas ya que ser judío es una categoría espiritual, que implica haber sido engendrado por los ángeles caídos. Por lo tanto, según Swift:

Los judíos son la semilla del maligno... ellos son la descendencia de Lucifer, razón por la cual hay judíos negros, rojos, amarillos y blancos debido a que esta semilla mestiza ha sido sembrada en cada raza... y los más malvados son los cainitas surgidos de la seducción de $\mathrm{Eva}^{37}$.

\footnotetext{
34. Wesley Swift, Snake Nest, 13 de noviembre de 1962, https://swift.christogenea.org/

35. Wesley Swift, America's So Great a Salvation, 7 de septiembre de 1963, https://swift.christogenea.org/

36. Wesley Swift, Snake Nest, 13 de noviembre de 1962, https://swift.christogenea.org/

37. Wesley Swift, When Flesh Puts on Light, 24 de septiembre de 1961, https://swift.christogenea.org/
} 
Swift aseguraba que estos últimos son los más peligrosos porque son los descendientes de Eva y, por lo tanto, son los grandes conspiradores ${ }^{38}$. La interpretación de la descendencia cainita como producto de una semilla infiltrada por el Diablo entre la generación adámica funciona como un espejo del temor a la infiltración comunista en la sociedad y política estadounidense ya que en ambos casos la ansiedad se concentra en la capacidad de las fuerzas ajenas para infiltrarse corromper desde adentro. Swift aseguraba que "aquí en los Estados Unidos tenemos dos millones de descendientes del Dragón. Están en nuestras ciudades. Y están en la política. La semilla del Dragón está en Washington y rodea al Señor Kennedy con malos consejos" ${ }^{39}$.

Si desde la década anterior ya estaban presentes en el discurso de Swift todos los elementos constitutivos de su demonología, a partir de 1960 -como se puede notar en las fechas de los sermones citados- el pastor se dedicó con más vehemencia a explicar y fundamentar sus argumentos demonológicos, que se vuelven más radicales. Si bien Swift partía de la base de que el Estado federal estaba infiltrado por agentes sionistas, su rechazo al presidente Kennedy era significativo. La política integracionista del presidente junto con el fracaso de la Bahía de los Cochinos era entendida por Swift como una traición a su país y a su raza. Swift denominaba a esta conspiración como Beast System, en alusión a la literatura escatológica judeo-cristiana ya que según el pastor, "existe una Bestia cuando hay oposición a Dios y cuando las fuerzas satánicas buscan destruir el nivel espiritual de los hijos de Dios" ${ }^{40}$. En consecuencia, el Beast System es la instalación terrenal del reino diabólico a través de instituciones políticas y financieras cuyo objetivo es "la conquista aplastante y la absorción de la civilización blanca cristiana"41.

La construcción demonológica de Swift permite vincular este pensamiento conspirativo con la figura del diablo judeocristiano, representante de todo lo perverso del mundo, lo cual recae sobre la imagen del judío al combinarse con la teoría de las dos semillas y el mito de la conspiración judía internacional. De este modo, para Christian Identity esta es la reproducción terrenal de la conspiración de los ángeles caídos contra Dios, constituyéndose en una teoría conspirativa cosmogónica y, por lo tanto, combatirla se vuelve no solo una misión política, sino también sagrada.

38. Wesley Swift, When the Canaanites Leave the House of God, 9 de agosto de 1962, https://swift. christogenea.org/. El pasaje bíblico que le confirma a Swift esta creencia es Juan 8:44, donde Jesús les dice a los judíos que "Ustedes tienen por padre al demonio y quieren cumplir los deseos de su padre".

39. Wesley Swift, The Seed of the Dragon, 1 de septiembre de 1961, https://swift.christogenea.org/

40. Wesley Swift, Mechanics of the Kingdom, 26 de noviembre de 1961, https://swift.christogenea.org/

41. Wesley Swift, With Violence Shall Babylon Be Cast Down, 10 de junio de 1964, https://swift.christogenea.org/ 


\section{Escatología}

La escatología judeocristiana es un tipo de cosmovisión intrínsecamente asociada al destino de Israel. Puesto que Christian Identity considera que los hombres blancos del mundo son literalmente los descendientes de las tribus israelitas, es coherente que su discurso teo-político adopte el formato escatológico a la hora de explicar el final de los tiempos, augurado como la derrota definitiva del "judaísmo internacional".

La escatología construida por Wesley Swift resignifica, sobre todo, el imaginario del excepcionalismo estadounidense, el cual supone una predestinación nacional que, durante el periodo aquí abordado, se asoció con los temores escatológicos de época derivados del terror al holocausto nuclear y la pretensión norteamericana de imponerse como única potencia hegemónica mundial.

Por lo tanto, la doctrina Identity sobre el fin de los tiempos sostiene la necesidad de destruir al enemigo por medio de una guerra armada directa que elimine al "Sistema de la Bestia” infiltrado en las naciones blancas. Esta guerra conformaría el Armagedón previo a la instauración del Milenio de Cristo en la tierra. Así, la escatología es parte esencial del culto ya que el mismo asegura que la raza adámica, está atravesando el periodo de los "últimos días" y, por lo tanto, un momento de crisis que, una vez superado mediante un esfuerzo humano, ejecutará el castigo de los perversos y beneficiará a los justos.

Estas raíces milenaristas de Christian Identity se remontan al anglo-israelismo, el cual era pre-milenarista, es decir que cree en que la Segunda Venida de Cristo precederá al Milenio. En los Estados Unidos esta visión ha predominado entre los círculos protestantes desde principios del siglo XX, sobre todo por medio de la articulación hecha por John Nelson Darby, fundador del dispensacionalismo. A la idea de que las profecías se cumplirán en un futuro indefinido, Darby sumó la noción del "rapto", por medio del cual Dios llevaría a sus elegidos al cielo durante el conflictivo periodo de las tribulaciones proféticas $^{42}$. Sin embargo, Identity se opone fervientemente al rapto ya que supone que los elegidos deben ser parte activa de la batalla final. En consecuencia, Swift promulgaba la necesidad de la violencia directa: "sólo quiero advertir a los cristianos tontos de hoy que no seremos evacuados. No vamos a escaparnos del mundo y entregárselo al diablo. Ese no es el programa de Dios. Vamos a quedarnos aquí. Vamos a derrotar al enemigo"43.

De este modo, su escatología era post-milenarista, es decir que la Segunda Venida de Cristo ocurriría luego de que el Milenio sea instaurado en la tierra con esfuerzo

42. Esta visión encuentra inspiración en el Evangelio de Mateo, que anuncia una gran tribulación que será llevada a cabo por los elegidos (Mt. 24: 15-22).

43. Wesley Swift, Russia, Red China, and the Western World, 22 de julio de 1963, https://swift.christogenea.org/ 
humano. La escatología de Wesley Swift se construyó con base al rol que la raza blanca debería tomar en la batalla final. En la teología de Christian Identity la violencia es la condición sine qua non para que el reino de Satán sea derrotado. Tal violencia supone el total compromiso de la raza adámica, por lo que Swift los interpelaba diciéndoles que "vuestro trabajo como cristianos estadounidenses es obstruir todo lo propuesto por las Naciones Unidas... todo lo que tenga sabor a socialismo, todo lo que no sea cristiano. Todo lo que sea no-blanco y que destruiría nuestra sociedad" ${ }^{4}$.

El imaginario del excepcionalismo norteamericano jugó un rol fundamental en la construcción escatológica del pastor, quien consideraba que los Estados Unidos es la nación elegida para derrotar al dragón e instalar el reino de Dios: "hay una Nueva Jerusalén. Y está aquí en los Estados Unidos". ${ }^{45}$ El contexto de temores nucleares que estaba atravesando los Estados Unidos durante la Guerra Fría se ligaba íntimamente con los imaginarios escatológicos cristianos. En tal coyuntura, el libro del Apocalipsis cobró una singular importancia al poseer un lenguaje sobre el "fin de los tiempos" similar al de los supuestos efectos ecológicos podrían producirse en caso de que ocurriese un holocausto nuclear global.

Por otra parte, como bien sugiere Andrew Weigert, ahora las armas nucleares, es decir las armas del "final de los tiempos" estaban en manos del hombre (Weigert, 1988, p. 188), hecho que incentiva la motivación Identity de que sea el esfuerzo humano el que traiga la tribulación que permitirá la construcción del Milenio de Cristo. Sobre ello decía Swift que: "la Escritura menciona que este es el modo en que las hordas del dragón, el poder de Lucifer, y todas estas fuerzas van a ser derrotadas. Pueden usar bombas atómicas y todo el fuego y humo, pero las masas de las hordas de Lucifer serán vencidas" 46 .

Un efecto de los movimientos milenaristas es su tendencia hacia una politización que, en la mayoría de los casos - pero no siempre - se vuelve sumamente violenta. La razón de esta radicalización es consecuencia de la cosmovisión dualista propia de la escatología judeocristiana, la cual divide al mundo en justos y pecadores y augura el triunfo de los primeros por sobre los segundos, los cuales son simbolizados por poderes políticos extranjeros que acosan a Israel, el pueblo elegido. Razón por la cual los apocalipsis suelen ser textos surgidos en periodos de crisis.

Quienes se vuelcan a las creencias escatológicas son personas que se creen oprimidas -en este caso son sectores blancos que se sienten desposeídos por la pérdida de

\footnotetext{
44. Wesley Swift, Cities of the Anti-Christ, 24 de marzo de 1963, https://swift.christogenea.org/ 45. Wesley Swift, The Shaking Earth, 22 de febrero de 1962, https://swift.christogenea.org/ 46. Wesley Swift, The Power of the Resurrection, 2 de abril de 1955, https://swift.christogenea.org/
} 
categoría que creen estar experimentando durante las dos décadas posteriores a la inmediata posguerra-, afectadas por poderes extranjeros -el "judaísmo internacional" y que carecen de los medios para derrocar al poder opresor. Para ello, creen que deben abastecerse de medios militares para derrocar al gobierno infiltrado por las "diabólicas" fuerzas judeo-comunistas y poder construir su propia teocracia blanca. Así, al combinar las esperanzas en un futuro mejor con la política material que permitirán juntas construir la "Nueva Jerusalén", la escatología se convierte en un factor que promete un futuro lleno de paz y salvación, tal como es augurado por el Apocalipsis de Juan ${ }^{47}$.

Así como la demonología de Wesley Swift se consolidó a partir de la década de 1960, la escatología también cobró mayor importancia durante tal periodo. Ambas estaban vinculadas ya que la explicación del origen y la persistencia del mal en el mundo se conjuga con la aseveración de su futura derrota por las fuerzas divinas. Por eso mismo, demonología y escatología crecen juntas en la teología del pastor californiano. Sin embargo, esta última fue aumentando año a año como consecuencia de la certeza en la inminencia del fin de los tiempos. Por tal razón, el discurso escatológico de Swift se intensificó entre 1964 y 1965, siendo a partir de esos años cuando los sermones se volcaron principalmente en tal dirección, la cual se suma al llamado político a la extrema derecha nacional.

La construcción teo-política de Swift contribuyó en la formación de diferentes experimentos que, especialmente durante la segunda generación de pastores Identity, se vinculan de un modo u otro a su discurso, el cual convocaba a los ciudadanos blancos a moverse políticamente hacia la derecha más extrema. La intensión de todos estos debía ser la misma: "un derechista ama su nación, su religión y a su raza. Un derechista es alguien que quiere ver la preservación de su raza y su nación y que no desea verlas mestizadas o dominadas por los poderes del mal. Un derechista es quien se opone al comunismo"48.

Según Michael Barkun, Christian Identity ha dado lugar a seis tipos diferentes de acción política, entre las cuales dos se insertan dentro de las normas del sistema, dos se colocan por fuera de ellas y dos permanecen en el límite entre ambas tendencias. Las dos primeras consisten en, por un lado, una retórica que interpela a que el sistema legal de los Estados Unidos se adapte a las leyes bíblicas y, por otro, en la inserción de candidatos Identity en el sistema político oficial.

En cambio, las tendencias ilegales implican la organización de campañas terroristas contra el Estado y la secesión territorial, estilo también llamado separatismo blanco, lo cual en definitiva no es otra cosa que la nueva forma de la retórica y la práctica

47. Apocalipsis 21, consultar Rowland (1982).

48. Wesley Swift, Russia, Red China, and the Western World, 22 de julio de 1963, https://swift.christogenea.org/ 
segregacionista tradicional. Por último, los estilos intermedios, profundamente ambiguos, consisten en la conformación de comunidades autosuficientes y aisladas del resto de la sociedad y en el desarrollo de políticas extremadamente localistas que desconocen la autoridad del gobierno federal y estadual (Barkun, 1997, p. 200).

La retórica política de Wesley Swift, en mayor o menor medida, puede rastrearse hasta cada una de estas tendencias, todas las cuales comparten la idea en la imperiosa necesidad de cambiar el sistema político oficial y reemplazarlo por uno que sirva a los intereses de la ciudadanía blanca desde los parámetros de la religiosidad Identity. Principalmente, Swift afirmaba que "no estamos interesados en la democracia. Nosotros estamos interesados en la teocracia. No existe un gobierno más elevado que una república guiada por Dios, que una teocracia con su pueblo representado en el parlamento"49.

Por lo tanto, es la Iglesia en versión Identity la que debe constituirse como culto de un Estado capaz de materializar sus principios en legislaciones supremacistas blancas y nativistas. En tal sentido, expresaba que "la Biblia te pide que discrimines y creo que es un buen consejo a seguir" ${ }^{50}$. Lo significativo de esta visión es que la Biblia es igualada en importancia a la Constitución estadounidense. Swift considera que estas últimas fueron escritas con base a las necesidades de la raza adámica en los Estados Unidos: "la constitución de Estados Unidos es un documento extraordinario y ciertamente la constitución más extraordinaria en la historia del hombre... La constitución fue inspirada"51.

El discurso político de Christian Identity es resultado de su teología. Se convierte, de este modo, en un ejemplo de la puesta en práctica del imaginario paranoide presente en la demonología y la escatología del culto. El rol de Wesley Swift en este aspecto ha sido principalmente retórico. Fueron los pastores de segunda generación los que han llevado a la práctica los distintos tipos de experimentos teo-políticos en los que se ha embarcado el culto desde la década de 1970. En tal sentido, la eclesiología es el ámbito en el que pueden observarse las pugnas internas entre los diferentes sectores de la extrema derecha norteamericana.

Es necesario remarcar que los diferentes estilos políticos que adoptó el extremismo de derecha de posguerra no son necesariamente exclusivos de Christian Identity ni poseen una clara interconexión entre sí. Si bien la extrema derecha tiene la característica de ser variada y cismática, los límites difusos, las mutuas influencias y la combinación de estilos también reflejan la capacidad aglutinadora del culto. En cierto sentido el mismo actúa como una fuerza

49. Wesley Swift, Why the Church Must War On, 16 de mayo de 1965, https://swift.christogenea.org/ 50. Wesley Swift, Why Censorship Will Not Work in God's Kingdom, 15 de diciembre de 1962, https://swift. christogenea.org/

51. Wesley Swift, The Message to the Nation, Church, and Throne, 9 de septiembre de 1962, https://swift. christogenea.org/ 
centrípeta capaz de reunir las diferencias debido a un discurso teológico que por su naturaleza universalista interpela a la derecha racista explicándole que la izquierda es diabólica y la derecha política es sagrada porque responde a los mandatos divinos. Así, la flexibilidad de Christian Identity resulta muy útil a la hora de establecer estos contactos, al menos por el reconocimiento de un enemigo en común y de una misma necesidad política combativa del enemigo.

\section{Conclusión}

Christian Identity se construyó con base a la concepción identitaria nacional/racial norteamericana más esencial dentro de la hegemonía blanca. Swift recuperó y adaptó diferentes tradiciones judeocristianas junto con un conjunto ecléctico de escritos racistas de diferente tipo y origen. Al sistematizar su teología es posible descubrir en ella los parámetros culturales básicos de su país en su particular clima de época. Especialmente es el excepcionalismo estadounidense el que está presente en la hegemonía discursiva del país y, por lo tanto, también en el discurso de Wesley Swift.

Por otra parte, la resignificación de estos imaginarios entre la extrema derecha del siglo XX dio lugar a un tipo de racismo antisemita de tinte espiritual, el cual englobó bajo la figura del judío el rechazo norteamericano a lo extranjero -lo anti-americano-, lo inferior -lo racialmente diferente- y lo demoníaco - lo anti-excepcional-. Por eso mismo el antisemitismo se ha constituido como un tipo de racismo "superestructural" capaz de aglutinar a la totalidad de las tendencias racistas del país y que explica todas las crisis de identidad atravesadas durante el siglo XX y XXI, es decir todas aquellas en las que se ve amenazado el discurso hegemónico del excepcionalismo.

Tal es el sentido en el que actúa Christian Identity. Así, el mito de la conspiración judía internacional al ser reapropiado por los sectores que volvieron literal el imaginario de los Estados Unidos como un "Nuevo Israel", pudo ser capaz de englobar y conjugar, bajo los parámetros del clima de época, al anticomunismo, a la segregación racial y al estilo paranoide.

A su vez, este estilo que fue compartido durante la Guerra Fría tanto por la política oficial como por la extremista supone que el conflicto bipolar sea interpretado en términos escatológicos. Muchos encontraron representación únicamente volcándose hacia la extrema derecha, que asocia fervientemente el anticomunismo oficial con el mito de la conspiración judeo-bolchevique, volviendo identificable al enemigo a diferencia de otros sectores que lo mantenían abstracto.

En este contexto específico, la teología de Wesley Swift brindaba respuestas trascendentales a las situaciones y ansiedades que afectan a la población blanca estadounidense en general y que preocupa particularmente a los sectores más conservadores, fácilmente 
seducidos por el extremismo político. Específicamente, Swift retomó los argumentos racistas tradicionales y los combinó con su resignificación de la teología judeocristiana para explicar que la raza es una cuestión biológica que refleja materialmente la esencia espiritual de un ser. Esta concepción, por lo tanto, constituyó un complejo paradigma racialista/racista que atraviesa toda la teología del pastor, la cual, desde su soteriología, cristología, antropología, demonología, y escatología interpela a su audiencia a actuar en relación con los conflictos sociales que atravesaban los Estados Unidos.

\section{Referencias}

[1] Angenot, M. (2010). El discurso social. Los límites históricos de lo pensable y lo decible. Siglo XXI.

[2] Barkun, M. (1997). Religion and the Racist Right: The Origins of the Christian Identity Movement. The University of North Carolina Press.

[3] Bell, D. (2008). The Dispossessed. En D. Bell (ed.), The Radical Right (pp. 1-45). Transaction Publishers.

[4] Bochicchio, A. L. (2020). Maternidad republicana durante la Guerra Fría en Estados Unidos: amas de casa, anticomunismo y racismo. Huellas de Estados Unidos. Estudios, perspectivas y debates desde América Latina, 18, 44-64. http://www.huellasdeeua.com/ ediciones/edicion18/02_Ana_Laura_Bochicchio_pp.44-64.pdf

[5] Brennan, M. (2008). Wives, Mothers, and the Red Menace: Conservative Women and the Crusade against Communism. University Press of Colorado. https://doi.org/10.2307/j.ctt1d8h9s3

[6] Bristowe, S. (1927). Sargon the Magnificent. The Covenant Publishing.

[7] Carroll, C. (1900). The Negro a Beast. American Book and Bible House.

[8] Cohn, N. (1988). El mito de la conspiración judía mundial. Raíces.

[9] Engelhardt, T. (1997). El fin de la cultura de la victoria. Estados Unidos, la guerra fría y el desencanto de una generación. Paidós.

[10] Federal Bureau of Investigation (FBI), Estados Unidos. https://archive.org/details/ SWIFTWesleyA.HQ157355454141206pp/page/n19/mode/2up

[11] García Bazán, F. (2009). El gnosticismo: esencia, origen y trayectoria. Guadalquivir.

[12] Gunn, T. J. (2009). Spiritual Weapons. The Cold War and the Forging of an American National Religion. Praeger.

[13] Hofstadter, R. (1996). The Paranoid Style in American Politics and Other Essays. Harvard University Press.

[14] Isenberg, N. (2016). White Trash. The 400-Year Untold History of Class in America. Penguin Books.

[15] Kaplan, J. y Weinberg, L. (1998). The Emergence of a Euro-American Radical Right. Rutgers 
University Press.

[16] Ceplair, L. (2011). Anti-Communism in Twentieth-Century America. A Critical History. Praeger.

[17] Laville, H. (2017). Organized White Women and the Challenge of Racial Integration, 1945 1965. Palgrave Macmillan.

[18] Lindquist Dorr L. (2004). White Women, Rape \& the Power of Race in Virginia, 1900-1960. The University of North Carolina Press.

[19] Roberts, C. H. (2003). Race over Grace. The Racialist Religion of the Christian Identity Movement. iUniverse.

[20] Roy, R. L. (1953). Apostles of Discord. A Study of Organized Bigotry and Disruption on the Fringes of Protestantism. The Beacon Press.

[21] Rowland, C. (1982). The Open Heaven. A Study of Apocalyptic in Judaism and Early Christianity. SPCK.

[22] Sarna, N. (1970). Understanding Genesis. Schocken Books.

[23] Simonelli, F. J. (1999). American Fuehrer. George Lincoln Rockwell and the American Nazi Party. University of Illinois Press.

[24] Swift, W. (s.f.). Corpus de sermones (1953-1967). Dr. Wesley Swift Library at Christogenea.org, s/f. https://swift.christogenea.org/

[25] Weigert, A. J. (1988). Christian Eschatological Identities and the Nuclear Context. Journal for the Scientific Study of Religion, 27(2), 175-191. https://doi. $\operatorname{org} / 10.2307 / 1386714$

[26] Wilson, J. (1880). Lectures on Our Israelitish Origin. Nabu Press. (Original publicado 1840). 